\title{
Inclusive education and Barrierefreiheit: some social-epistemological considerations
}

\section{Kai Horsthemke}

To cite this article: Kai Horsthemke (2017) Inclusive education and Barrierefreiheit: some social-epistemological considerations, Ethics and Education, 12:1, 23-34, DOI: 10.1080/17449642.2016.1270508

To link to this article: http://dx.doi.org/10.1080/17449642.2016.1270508

册 Published online: 31 Jan 2017.

Submit your article to this journal

III Article views: 55

Q View related articles ๘

View Crossmark data $₫$ 


\title{
Inclusive education and Barrierefreiheit: some social-epistemological considerations
}

\author{
Kai Horsthemke \\ Bildungsphilosophie und Systematische Pägagogik, Katholische Universität Eichstätt-Ingolstadt, Eichstätt, \\ Germany
}

\begin{abstract}
Barrierefreiheit is a key term in the German inclusion movement, in education and more generally. Sometimes translated as'accessibility', it refers not just to absence of barriers but to freedom from barriers, which in turn indicates a significant social and ethical component. It signals an active, conscious intervention by agents, a consequence of agentic commitment towards crossing borders and overcoming boundaries. In this regard, this article seeks to provide an epistemological analysis and illustration of what 'inclusive', 'barrier-free' education means, by examining three ideas within social epistemology: epistemological access, epistemic paternalism and epistemic justice. In so doing, it articulates a position that might be called 'context-sensitive realism', which cautions against not only constructivist theoretical leanings but also the anti-individualism that characterises a substantial portion of the inclusive education literature.
\end{abstract}

\section{KEYWORDS}

Barrierefreiheit; contextsensitive realism; epistemological access; epistemic justice; epistemic paternalism; inclusion; social epistemology

\section{Introduction: the idea of Barrierefreiheit}

Barrierefreiheit is a key term in the German inclusion movement, in education and more generally. Sometimes translated as 'accessibility', it refers not just to absence of barriers but also to freedom from barriers, which in turn signals a significant social and ethical component. It indicates an active, conscious intervention by agents, a consequence of agentic commitment towards crossing borders and overcoming boundaries. Barrierefreiheit is often understood to be a basic enabling condition for inclusion, which refers to people with and without relevant disabilities living, learning and working together as a matter of course. (The notion of 'relevant' is important here, because everyone has strengths, as well as weaknesses, that arguably require some degree of attention. ${ }^{1}$ ) Yet, there is a significant distinction between inclusion and freedom from barriers. Whereas inclusion is seen as never complete, as a never-ending process, with inclusive institutions at best approximating a perfect or end state (see Grosche 2015), Barrierefreiheit sometimes also seems to portray such an ideal condition or state. Barriers include everything from a lack of ramps or chairlifts to difficult or incomprehensible texts. But barriers also include mental barriers. These take the form of preconceptions and prejudices towards the disabled or impaired on the part of those without relevant disabilities. Mental barriers also include a lack of awareness or appreciation of the 
kinds of obstacles encountered by many people (including limitations because of social origin, or language and cultural barriers) and of how these can be overcome. So a barrier-free state would be one of mindfulness and empathy, over and above the absence of physical obstacles, borders and boundaries. Barrierefreiheit is a cross-sectional theme that touches on multitudinous aspects and areas of our daily existence, how we get around, how we communicate and how we get along with one another.

To illustrate the epistemological significance of 'translation' and 'border crossing' (two sub-themes of the 2016 INPE conference theme, 'Philosophy as translation and the understanding of other cultures'), and to explore its educational implications, I will focus on the demands imposed by the accommodation of those with disabilities. What is involved, epistemologically, in inclusive, 'barrier-free' education? Other pertinent questions are: Could inclusion conceivably violate the norms of educational justice? ${ }^{2}$ To what extent do those with cognitive disabilities benefit from inclusive, barrier-free educational practices? And what, if anything, does inclusion offer those without relevant disabilities? These are also questions that turn on the epistemological issue of understanding other cultures. A quick response to the last question might be that, at the very least, many solutions developed for the sake of Barrierefreiheit also benefit those without disabilities. Thus, ramps and lifts help not only those with temporary and permanent impairments but also parents with prams, young children and the aged. What is required by people with learning difficulties - like texts in accessible language and unambiguous accompanying illustrations (here we encounter the normative impulse behind 'translation') - will also benefit those with a weak grasp of the language or geographic location in question, and those who are illiterate or barely literate. An additional, albeit more self-serving, consideration is that people without present impairments may, at a later stage in their lives, benefit from the absence of barriers. Finally, and perhaps most importantly, those without relevant handicaps are likely to develop a greater sensitivity towards those who are so disabled and to increase their ability to take a pro-active role in a world of difference, diversity and heterogeneity. Martha Nussbaum, referring to education and inclusion in particular, claims that the practice of 'mainstreaming' children with disabilities is defensible because 'of the benefit to the mentally disabled child, who will be given more incentives to develop cognitively and who may be less likely to be stigmatised as type apart' (Nussbaum 2006, 205). It is also defensible on the grounds of 'the benefit it offers to so-called normal children, who learn about humanity and its diversity by being in a classroom with a child who has unusual impairments' (ibid.). These children 'learn to think for themselves, their own weaknesses, and the variety of human capability, in a new way' (Nussbaum 2006, 206).

Inclusion, then, cannot function without Barrierefreiheit. When and where there are obstacles, participation in social, cultural and political life is significantly impaired. The ethical dimension of inclusion and barrier-free education is only one of several areas of possible philosophical investigation. My concern here is less with the ethical than with the epistemological dimension, which nonetheless retains a bearing on the question of educational justice. This paper attempts to provide an analysis of the following three epistemological aspects, ${ }^{3}$ both with regard to the conceptions of inclusion justice within education, and in terms of the connections and tensions between them:

- epistemological access (Morrow 2007; see also Lotz-Sisitka 2009; Bekker 2013; Walton 2013; Walton and Bekker 2013), 
- epistemic paternalism (Goldman 1992) and

- epistemic justice (Fricker 2007).

\section{Epistemological access}

There is a tendency to associate inclusive education with learners with various kinds of disability, especially those with 'special educational needs' (Walton and Bekker 2013, 442). This is a rather problematic label. As Elizabeth Walton and Tanya Bekker have argued, a learner diagnosed with cerebral palsy (which is commonly identified as a'special need') may require considerably less help from her teacher than a young person who heads a household (which is not usually considered a 'special need'; 458). Less narrowly conceived, however, inclusive education targets the various ways in which marginalisation and disadvantage, generally, occur in educational contexts and situations - in other words, all kinds of exclusion from those opportunities that ought to characterise access to learning. Among other things, barrier-free pedagogy might be understood as providing learners with epistemological access. In other words, and importantly, inclusive education is 'an issue of how epistemological access is enabled or constrained by the pedagogical choices we make' (ibid.). According to Walton and Bekker:

In inclusive education discourse, 'exclusion' is used to describe not only the physical non-presence of children, but also the variety of factors that impede full and fair access to and participation in school activities ... access to the curriculum, learning and teacher attention, access to peer and social interactions ... and access to school resources, extra-curricular activities and participation in school traditions. $(2013,450)$

The term 'epistemological access' was first coined by Morrow (2009, iv), the late South African educational philosopher who played a significant role in post-apartheid educational reform. Beginning with the idea that 'teaching is conceptually linked to the idea of access', Morrow made a conceptual distinction between two kinds of access not commonly distinguished from each other, formal and epistemological access. Formal access is held to be 'a matter of access to the institutions of learning, and it depends on factors such as admission rules, personal finances, and so on' (Morrow 2007, 2). Epistemological access, on the other hand, is access to the goods that institutions distribute to those it formally admits and, as the main good distributed by educational institutions, to knowledge - which must be understood here as encompassing all kinds of practical and theoretical knowledge. Morrow considers formal access to be important in the light of South Africa's 'history of unjustifiable institutional exclusions' (ibid.). Epistemological access on the other hand, is 'what the game is about. One way of characterising teaching is to say that it is the practice of enabling epistemological access' (ibid.; see also 8, note 6, and 39).

From all this it follows that the question, 'Epistemological access for whom?' (Walton and Bekker 2013, 443), appears to receive the rather uninteresting answer, 'Everyone who is educable'. But this by no means renders the concept redundant. Given that education and, in particular, classrooms are increasingly characterised by diversity and heterogeneity of learners (commonly with vastly different features, competences, learning needs and learning barriers), it is clear that a'one-size-fits-all' approach does not (any longer) meet current challenges (ibid.; see also Walton 2013, 508). ${ }^{4}$ This will also have a bearing on the breadth and depth of the access in question. On the other hand, responsive educators also need to protect 
themselves from pedagogical paralysis: if the uniqueness of learners necessitates, respectively, unique teaching strategies, then an overemphasis of the individual could soon lead to a culture of overemphasising difference. It could be argued that it is not so much a matter of diversity in general but rather of emphasis on pedagogically relevant differences; that is, of judging when and to what extent individual and group differences are pedagogically significant, of planning lessons that are meant to provide access for all, etc. The quality of pedagogy, i.e. how educators work with knowledge, can be seen either as overcoming barriers or as preventing access. Heila Lotz-Sisitka (2009), building on Morrow's ideas and on the basis of several case studies, lists several ways in which teaching practice can constrain epistemological access, or retain existing barriers:

- through teacher's failure to bridge the divide between the concrete and the abstract, or between everyday knowledge and school knowledge;

- through teachers' failure to interpret the demands of set curricular standards and subsequent limitation of the scope and level of access in relation to these standards;

- through reliance on teacher knowledge only, which may in itself be limited, and subsequent limitation of the scope and depth of access to new knowledge; and

- through inadequate feedback on tasks, and subsequent failure to enable learners to deepen their understanding or address misconceptions (see also Walton and Bekker 2013, 452).

In the remainder of this section on epistemological access, I discuss three problems I have identified in the relevant literature, pertaining to the more or less explicit endorsement of a constructivist conception of knowledge, its critique of individualism and the characteristics of the inclusive educator, respectively.

\section{Knowledge as 'contested' and 'constructed'}

First, it would appear that a substantial portion of the literature on inclusion understands epistemological access in constructivist terms, i.e. in terms of learners being 'active participants in the construction of their knowledge' (Bekker 2013, 467). Thus, Bekker writes:

Knowledge is frequently presented as contested (in other words, it is not presented as a fixed body of information, but rather as being constructed; contrasting points of view or interpretations and potentially conflicting forms of knowledge are discussed) instead of as universally accepted by all (that is, as a one-dimensional body of truth). (476)

The idea is that substantive conversation is needed in multicultural or intercultural contexts, where knowledge is seen as emanating from specific social and cultural histories rather than as 'fixed'. From an inclusive education perspective, Michel Foucault's critique of epistemological hegemony and his analysis of how knowledge and truth are always part of systems of power are considered significant (Bekker; personal communication):

Each society has its own regime of truth, its 'general politics' of truth: that is, the types of discourse which it accepts and makes function as true; the mechanisms and instances which enable one to distinguish true and false statements, the means by which each is sanctioned; the techniques and procedures accorded value in the acquisition of truth; the status of those who are charged with saying what counts as true. (Foucault 1984, 73)

At least two concerns arise in this regard. The ideas of 'regimes of truth' and "'general politics" of truth' not only indicate a category mistake (in treating epistemological matters 
as necessarily inseparable from matters of social justice), but they are also dangerously close to relativism about truth. Is Foucault able to make these sorts of assertions consistently? If he is correct, then this is so only on the basis of his particular society's regime or 'general politics' of truth - in which case the question arises why others (i.e. those who do not belong to his particular society) ought to find his analysis compelling. If he is saying, however, that this particular truth holds transsocietally, then he has in effect opened the door to the (strong) possibility of there being other truths that are not confined to the contexts of society or culture. Either way, then, this account loses much of its intended force.

What is missing in the pertinent literature is an account, let alone a critical analysis, of the concept of knowledge. An examination of this idea may well demonstrate that the conceptualisation of constructivism as an epistemology is highly problematic. The most significant problems are posed by relativism (both about knowledge and about truth) and by constructivism's difficulty to distinguish between knowledge and mere belief, between science and non-science (especially dogma and superstition). In addition, the common assertion that knowledge is 'contested' seems to draw its strength entirely from this lack of definition and conceptual clarity. Once an account of the different uses of the term 'knowledge' and circumspect definitions is furnished, much of the putative basis for 'contestation' will have been eroded. By the time students have completed their undergraduate teacher training, many have been thoroughly indoctrinated with constructivism. According to Duffy and Cunningham (1996), and also Windschitl (2002), one of the most difficult underpinnings of constructivism for educators to embrace is that there are no universal truths and that constructivism by its very nature is not compatible with more objective forms of knowing. No wonder, one might respond, since this can only be apprehended as either a 'universal truth' itself, or in terms of an 'objective form of knowing'. It would appear, then, that in an important respect constructivism is self-undermining: either there are no universal truths (or objective forms of knowing), except this particular one; or the statement in question does not itself constitute a universal truth, or objective form of knowing. More to the point, it should be noted that the logic of neither inclusion (and Barrierefreiheit) nor epistemological access requires adoption of a constructivist epistemology. However, this is not the place for a detailed critique. My sketchy remarks here are unlikely to persuade anyone that constructivism, for example, should be rejected. They merely serve to underline my misgivings about bestowing special status in education on a theoretical orientation that is deeply problematic. As Lotz-Sisitka claims, 'education has a critical role to play in preparing children to live in the world' (Lotz-Sisitka 2009, 71; emphasis added). This arguably requires that those who so prepare children live there, too. Frankly, I cannot see constructivism making a substantial contribution to this preparation process, neither with regard to children nor those with relevant impairments.

\section{The ideology of individualism}

Moreover, there is a tendency in the inclusive education literature to relate the 'deficit way of understanding difference' to 'the ideology of individualism' (Walton \& Bekker 2013, 454). Research that explores individual experiences of disability has been subject to considerable critique. For example, Michael Oliver distinguishes between the individual and the social model of disability (Oliver 1990, 2004). He rejects the individual (or 'medical') approach because it locates the 'problem' in individual deficit and sees its causes as 'stemming from 
the functional limitations of psychological losses which are assumed to arise from disability' (Oliver 1990, 3). It therefore, he claims, does not take into account the structural (economic, environmental and cultural) barriers and exclusions that people with disabilities face. The argument is that making disability a personal or individual tragedy, requiring individual intervention, obviates the need to consider disabling practices and attitudes in society (or the classroom) as a whole. McCall and Skrtic (2009) contend, similarly, that collective action against oppression is forestalled by a focus on individual 'problems'.

It is perhaps ironic that Oliver's own approach is rather exclusive and judgemental. For example, he states that he does 'not intend to engage with the disapproving analyses that have been offered from those outside the [Disability Studies] Movement or in other parts of the academy' (Oliver 2004, 18). His point that 'the cultural environment in which we all grow up usually sees impairment as unattractive and unwanted' (4) certainly deserves to be taken seriously. Nevertheless, while he may be correct in stating that 'parents' feelings towards, and treatment of, a child born with an impairment are dependent upon what they have learned about disability from the world around them' (4), the following conclusion appears to be counter-intuitive, to say the least:

people who acquire impairment later in life have already been immersed in the personal tragedy viewpoint and it is not therefore surprising that many of these individuals find it difficult to know how to respond in any other way. (5)

So, to view impairment acquired later in life as a personal tragedy is mistaken? And the disabled who do view their own condition in this way are wrong? Oliver seems to proceed by way of bald assertion here. In fact, there seems to be a false dichotomy at work in his binary distinction. Focusing exclusively on the social model of disability may entail losing sight of the individual who is disabled. It is not a matter of locating the 'problem' of disability in the individual but rather of individual recognition, of nurturing a sense of belonging in the individual and making sure that s/he does indeed 'belong'.

Walton agrees that 'inclusion has to be about an educational responsiveness to individuality', but also thinks that 'when individual differences are made a major focus, teachers cannot imagine that they can teach more than one child at a time' (personal communication):

Individualism assumes that if children work hard enough and apply themselves they should be successful. This shifts the blame for lack of school success onto the individual child as either being 'unable' to succeed given an inner deficit or 'unwilling' to succeed in terms of effort and application. (Walton and Bekker 2013, 454)

This characterisation of individualism seems to be mistaken. In fact, individualism by its very nature takes difference and individual capability seriously and disavows the deficit conception highlighted above. After all, disabled children (for example) do not constitute a faceless class: they are individuals, with varying needs and abilities. Nussbaum endorses the law's 'focus on protecting what most urgently needs protection: the claim of stigmatised children to be seen, and educated, as individuals' (Nussbaum 2006, 210; see also Lewin 2007, 34).

It follows that the attack on individualism is based on problematic assumptions. A relevant and legitimate target would, rather, be performativity in education, which seems to have the bureaucratic and pernicious streak correctly taken aim at above. 


\section{Epistemological access and the virtues of the inclusive educator}

Finally, providing a list of personal features or characteristics of educators who are capable of enabling epistemological access does not yield an explanation of why what these educators are mediating is (ipso facto) epistemological access. According to Bekker $(2013,477)$, educators 'who demonstrate pedagogical sensitivity and tact"show empathy' (i.e. they 'try to understand the learner's point of view'); they 'have a positive view of others' (i.e. they 'demonstrate trust and confidence in the worth, ability and capacity for growth, development and learning of the learners'); they 'have a positive view of self' (i.e. they 'see themselves as capable and have a quiet sense of confidence'); they demonstrate'authenticity' (i.e. they'are genuine and real in their interactions with learners'); they 'have a meaningful purpose and vision' (i.e. they'are committed to helping all learners to reach their potential'); and they'are sensitive and perceptive of the needs of others'. The challenge, then, would be to match the virtues of the inclusive, responsive teacher and the different ways in which and levels (e.g. of difficulty and complexity) at which she works with and presents knowledge, how she thinks about, orders and sequences the knowledge she teaches and the ways in which she works with the knowledge of others.

\section{Epistemic paternalism}

Assuming responsibility for one's own beliefs is only one concern among many in epistemology. Another concerns responsibility for the beliefs of others, through teaching, selection and control. This involves what Alvin Goldman calls 'epistemic paternalism' (Goldman 1992). It refers to the kind of knowledge, information or communication control that occurs in education and law and in various other kinds of social enterprises and relations. It means that certain kinds of information are often withheld or kept from people, for the benefit of the recipient of knowledge or information (for example, the learner). ${ }^{5}$ Goldman draws an analogy with parents who keep dangerous toys or other articles away from children, or who decide not to expose children to certain types of situation. A similar impulse, he says, is at work with shielding children, learners or people generally from certain facts or types of information. One might prefer to speak of 'parentalism' rather than 'paternalism'. For many, the latter has generally derogatory associations. Not only is it usually assumed to involve taking care of others while limiting their freedom and responsibility, but it also suggests a social order in which the father is the bearer of formal authority within the family. ('Maternalism' might go some way towards correcting the explicit androcentrism here, in its acknowledgement of informal, crucial and usually invisible familial authority, but it has a similarly gender-specific connotation.) Nonetheless, for the sake of conceptual simplicity, I retain Goldman's notion in what follows.

Usefully for present purposes, Goldman chooses to illustrate epistemic paternalism with examples from the realm of education. In particular, he mentions curriculum selection. Curricular materials are selected by school personnel at various levels; not only by educators, but also by boards of education and principals. What is involved in curriculum selection? Epistemic paternalism is concerned not only with the relevance, suitability and verity of what is taught but also with the level of cognitive and emotional ability and maturity of the learners. Most pertinent to this discussion, learners are not exposed to all possible views or ideas on a given subject. Not only are they generally exposed only to materials that are relevant 
and appropriate to their level of understanding, but opinions that are regarded as false or indefensible are also withheld by current educational authorities.

Wondering about the need for paternalistically motivated epistemic constraints, Goldman asks whether epistemic paternalism is 'really warranted' (214). A related question is whether it is 'desirable in terms of promoting truth and avoiding error' $(214-215,220)$. Logically speaking, epistemic paternalism is not necessary for education to occur. We could at least conceive of a situation where everything is taught indiscriminately, with little or no regard for its relevance, suitability and verity - a situation that nonetheless yields some kind of educational value. The more interesting question is whether epistemic paternalism is defensible, even desirable. The short answer seems to be - notwithstanding errors that are sometimes made in controlling knowledge and information - that, even with the best of intentions, it is defensible. As parents and educators, we select what we deem to be of value to pass on to the next generation. Since none of us can reasonably hope to assess all evidence for all theses personally, we often depend on the authority of others. Questions of epistemic desirability perhaps relate more to the reasons why selection decisions are made. An important consideration is that, unlike defensive teaching (see McNeil 1986) and indoctrination, epistemic paternalism is practiced for the benefit of learners. Thus, knowledge selection in education involves 'translation' as much as it involves dismantling barriers, for the sake of those at the receiving end of our pedagogical practices.

Goldman points out that epistemology has traditionally assumed that all those working with knowledge and justification have the same cognitive resources, skills and opportunities and that they operate without time constraints and the like. This is an idealised setting, he contends, which is endorsed neither by common sense nor by common experience.

[In] settings marked by different levels of expertise, by different opportunities for information gathering, by different levels of cognitive maturity and training, and by severe time constraints, idealized principles of communication do not apply. A social epistemology for the real world needs to take these constraints into account. (Goldman 1992, 224)

This is especially pertinent with regard to learners living with various kinds of disability. Epistemic paternalism needs to take seriously the positions, perspectives and experiences of those who live with impairments in a society where impairment is not considered the norm but is seen, rather, as 'unattractive and unwanted' (Oliver 2004, 4). This may help explain why paternalism remains epistemically warranted. A defensible paternalism that takes on the epistemic positions of the impaired will be likely to reflect a more accurate picture of social reality than an approach that assumes an idealised setting, in Goldman's sense. I next turn to the idea of epistemic justice.

\section{Epistemic justice}

Broadly, epistemic justice refers to the fair and equal distribution of epistemic benefits and burdens: it involves due acknowledgement of individuals as knowers with corresponding rights and obligations. In her influential account of epistemic injustice, Miranda Fricker distinguishes between two types of epistemic justice, testimonial and hermeneutical justice. Fricker refers to them as hybrid virtues (in that they both have an intellectual and an ethical component) that serve to countervail or prevent epistemic (i.e. respectively, testimonial and hermeneutical) injustice. Although they are experienced (and may be performed) individually, testimonial and hermeneutical injustice constitute not only individual harms: they 
originate within a social fabric of which the biases and prejudices that enliven and perpetuate them are a characteristic part. Contesting such injustices and harms, according to Fricker, requires 'collective social political change' (Fricker 2007, 8).

In order to bring about such change, what is required at a testimonial level is 'reflexive awareness of the likely presence of prejudice', and this 'anti-prejudicial virtue is the virtue of testimonial justice' (91-92). Testimonial justice, says Fricker, is 'both ethical and intellectual in character, at once a virtue of truth and a virtue of justice' (124). Thus, apart from being able to rely on the competence and sincerity of speakers (72), and apart from sensitivity (ibid.) and empathy (79), 'hearers need dispositions that lead them reliably to accept truths and to reject falsehoods' (115).

Like testimonial justice, hermeneutical justice is a hybrid virtue, says Fricker (174). What it is meant to counteract is hermeneutical injustice, which occurs when (members of certain) groups or communities lack the hermeneutical tools to make sense of their own social experience (146).' For something to be an injustice, it must be harmful but also wrongful, whether because discriminatory or because otherwise unfair' (151). When there is unequal 'hermeneutical participation with respect to some significant areas(s) of social experience, members of the disadvantaged group are hermeneutically marginalised' (153).

Given how prejudice affects various levels of credibility, this discussion raises the question whether the idea of epistemic (in-)justice (which, after all, in Fricker's analysis refers to the epistemic situation of women and blacks in a world dominated by men and whites) is at all relevant to inclusion of those with impairments. Testimonial justice appears as an original virtue of both justice and truth. Applied to the case of inclusion, it expresses the idea that the influence of a possible identity prejudice (in this case, against a person with cognitive disability or impairment) on the part of the (non-impaired) hearer has been recognised and corrected. Hermeneutical justice manifests itself in the reflective-critical sensitivity of the (non-impaired) hearer to any reduced understanding (or any failure to comprehend) incurred by the speaker (in this case, the person with cognitive disability) because of a gap in the collective hermeneutical resources. In other words, the hearer is aware of the fact that the speaker's apparent lack of understanding is'a function of a collective hermeneutical impoverishment, and he adjusts or suspends his credibility judgement accordingly' (7).

To take a relevant example of hermeneutical injustice suggested by Emily Robertson: having long been excluded from the development of an available framework for articulating their experience, 'recently people with intellectual disabilities have rejected the term 'retarded' as a slur although the field of 'mental retardation' has used it for years' (Robertson $2013,302)$. This indicates, Robertson asserts, that inclusion of the experiences and perspectives of marginalised groups in knowledge production can change the conceptual landscape in epistemically fruitful ways' (302).

\section{Further questions and concluding thoughts: context-sensitive realism}

This article has been concerned in the main with certain epistemological considerations pertaining to inclusive, barrier-free education. What possibilities for learning and the acquisition of knowledge exist for those with cognitive and physical impairments? Access to institutions of learning is not identical to epistemological access. An additional consideration is that learning possibilities, as well as the mediation and acquisition of knowledge, differ from person to person. Given that one cannot participate or be included everywhere or 
claim unlimited access for oneself, should one nonetheless be able to determine to what one has access? While perhaps desirable, this is clearly utopian. Especially in cases of limited autonomy and self-determination, a certain knowledge and information control is arguably both necessary and justified. In other words, the young and the cognitively impaired are not given unlimited access to knowledge and information. (Nor are any of us, for that matter, under any and all circumstances.) This may lead us to conclude that Barrierefreiheit, like inclusion, is never complete, a never-ending process, with barrier-free arrangements and institutions at best approximating a perfect or end state.

The controlled transfer of knowledge and information raises the question of epistemic justice. How ought one to accommodate the knowledge claims and the epistemic and cognitive abilities of those with relevant impairments? Under what circumstances can one speak of knowledge here? What would be the basis for inclusion within a knowledge community? Without being able to provide a comprehensive analysis here, I suggest that a context-sensitive realism offers a plausible response to these questions. It is concerned with a normative account: it deals with processes that ought or ought not to be called 'knowledge'. In other words, 'knowledge' is not ambiguous between various concepts of knowledge. What constitutes knowledge does not fluctuate with differences in people's cognitive abilities or with what their constructs, 'regimes' or'politics' are. It does acknowledge that people do not have the same cognitive resources, abilities and opportunities. They do not all act or operate in the absence of time constraints. Their situations are characterised by different levels of expertise, by different opportunities to access and gather information, by different levels of cognitive ability, maturity and training, and by considerable disparities in time constraints. This insight permits us to talk of different levels of knowledge, without implying relativism. Barrierefreiheit is not a case of 'anything goes', epistemologically. The knowledge in question remains characterised by the pursuit of truth and the avoidance of error. A relevantly disabled person's claims constitute 'knowledge' only if they are true. The same - obviously - goes for the claims of those without pertinent disabilities. Truth does not vary according to particular individuals, social or ethnic groups or different cultures. This serves to indicate why, as educators, we are more lenient in some cases than in others, but our leniency does not extend to condoning untruths or falsehoods.

\section{Notes}

1. As Martha Nussbaum explains, 'it would be progress if we could acknowledge that there really is no such thing as "the normal child": instead, there are children, with varying capabilities and varying impediments, all of whom need individualised attention as their capabilities are developed' (Nussbaum 2006, 210).

2. In this regard, Krassimir Stojanov examines the different responses provided in terms of distributive justice, participatory justice and recognitory justice (Stojanov 2015).

3. To be more precise, these are ideas within the fairly new field of social epistemology, understood here as concerned with the interpersonal and social practices and norms that influence and guide the search for knowledge.

4. It might seem, of course, given that 'differentiation' and 'personalization' are central to the discourse of learning, that it has been acknowledged that a 'one-size-fits-all' approach is not desirable (I owe this consideration to Naomi Hodgson). I simply report an observation within the literature on epistemological access here. An obvious drawback is that many educators may feel simply overwhelmed by the demand to attend to each individual's personal, differentiated needs, interests and capabilities. I return to this point below. 
5. The question might be posed now whether this is not a form of construction of knowledge. I do not think it is: it is, rather, a matter of knowledge selection. Even if one could attach the notion of construction to belief and justification, one could not meaningfully connect it with truth - unlike the notion of selection.

\section{Acknowledgement}

This paper was written as a contribution to the sub-project on inclusion and educational justice, part of a joint project, 'Inklusives Leben und Lernen in der Schule', based at KU Eichstätt-Ingolstadt and sponsored by the Freisinger Bischofskonferenz. I also wish to thank Naoko Saito, Naomi Hodgson and Rafal Godon for their insightful remarks on earlier drafts of this paper.

\section{Disclosure statement}

No potential conflict of interest was reported by the author.

\section{References}

Bekker, T. 2013. "Ensuring Epistemological Access." In Education Studies, edited by K. Horsthemke, P. Siyakwazi, E. Walton and C. Wolhuter, 463-485. Cape Town: Oxford University Press South Africa.

Duffy, T. M., and D. Cunningham. 1996. "Constructivism: Implications for the Design and Delivery of Instruction." In Handbook of Research for Educational Communications and Technology, edited by D. Jonnasen, 170-198. Mahwah, NJ: Lawrence Erlbaum Associates.

Foucault, M. 1984. "Truth and Power." In The Foucault Reader, edited by P. Rabinow, 51-75. New York: Pantheon Books.

Fricker, M. 2007. Epistemic Injustice: Power and the Ethics of Knowing. Oxford: Oxford University Press.

Goldman, A. I. 1992. "Epistemic Paternalism: Communication Control in Law and Society." In Liaisons: Philosophy Meets the Cognitive and Social Sciences, 209-225. Cambridge, MA: MIT Press.

Grosche, M. 2015. "Was ist Inklusion? [What is Inclusion?]" In Inklusion von Schülerinnen und Schülern mit sonderpädagogischem Förderbedarf in Schulleistungserhebungen [The Inclusion of Learners with Special Educational Needs in the Investigation of School Performance], edited by P. Kuhl, P. Stanat, B. Lütje-Klose, C. Gresch, H. Pant and M. Prenzel, 17-39. Wiesbaden: Springer.

Lewin, K. M. 2007."Improving Access, Equity and Transitions in Education: Creating a Research Agenda." Create Pathways to Access, Research Monograph No 1, June. Accessed June 28, 2016. http://www. create-rpc.org/pdf_documents/PTA1.pdf

Lotz-Sisitka, H. 2009. “Epistemological Access as an Open Question in Education.” Journal of Education 46: 57-79.

McCall, Z., and T. M. Skrtic. 2009. “Intersectional Needs Politics: A Policy Frame for the Wicked Problem of Disproportionality." Multiple Voices for Ethnically Diverse Exceptional Learners 11 (2): 3-23.

McNeil, L. H. 1986. Contradictions of Control:School Structure and School Knowledge. New York: Routledge \& Kegan Paul.

Morrow, W. 2007. Learning to Teach in South Africa. Cape Town: HRSC Press.

Morrow, W. 2009. Bounds of Democracy: Epistemological Access in Higher Education. Cape Town: HSRC Press.

Nussbaum, M. 2006. Frontiers of Justice: Disability, Nationality, Species Membership. Cambridge, MA: Belknap-Harvard.

Oliver, M. J. 1990. "The Individual and Social Models of Disability." Paper presented at the Joint Workshop of the Living Options Group and the Research Unit of the Royal College of Physicians on 'People with Established Locomotor Disabilities in Hospitals' July 23. Accessed June 30, 2016. http://disabilitystudies.leeds.ac.uk/files/library/Oliver-in-soc-dis.pdf

Oliver, M. J. 2004. "The Social Model in Action: If I Had a Hammer." In Implementing the Social Model of Disability: Theory and Research, edited by C. Barnes and G. Mercer, 18-31. Leeds: The Disability Press. 
Robertson, E. 2013. “The Epistemic Value of Diversity." Journal of Philosophy of Education 47 (2): 299-310. Stojanov, K. 2015. "Inklusion und Bildungsgerechtigkeit [Inclusion and Educational Justice]." [Concept paper as part of the joint project]. "Inklusives Leben und Lernen in der Schule [Inclusive Living and Learning in the School]", KU Eichstätt-Ingolstadt, 28 April.

Walton, E., and T. Bekker. 2013. "Pedagogy and Inclusion." In Education Studies, edited by K. Horsthemke, P. Siyakwazi, E. Walton and C. Wolhuter, 440-462. Cape Town: Oxford University Press South Africa. Walton, E. 2013. "Responsive Teaching." In Education Studies, edited by K. Horsthemke, P. Siyakwazi, E. Walton and C. Wolhuter, 486-510. Cape Town: Oxford University Press South Africa.

Windschitl, M. 2002. "Framing Constructivism in Practice as the Negotiation of Dilemmas: An Analysis of the Conceptual, Pedagogical, Cultural, and Political Challenges Facing Teachers." Review of Educational Research 72 (2): 131-175. 